\title{
An Active Modulation Scheme to Boost Voltage Utilisation of the Dual Converter with a Floating Bridge
}

\author{
Zhen Huang,Student Member, IEEE, Tao Yang,Member, IEEE, Pat Wheeler, Senior Member, IEEE, \\ Michael Galea,Senior Member, IEEE, Paolo Giangrande and Shajjad Chowdhury,Member, IEEE
}

\begin{abstract}
This paper proposes a capacitor voltage regulation method for the dual converter with a floating bridge for aerospace applications. This topology has previously been reported, but with a constrained voltage utilisation factor due to the need for capacitor voltage regulations. In this paper, the effect of switching states on the voltage variation of capacitor is quantitatively modelled and an enhanced space vector modulation scheme with current feedback is proposed to achieve an active control of the floating capacitor voltages. This proposed method also allows further exploitation and utilisation of converter voltage. The relationship between the allowed modulation index of dual converter and load power factor is obtained and expressed using a fitted polynomial equation. The advantages of the proposed method include boosted voltage utilisation and superior performance in term of capacitor voltage balance. These advantages have been proven through simulation and experimental results on $R L$ loads as well as with an open-end winding induction motor. The proposed modulation scheme can boost the converter voltage utilisation by at least $10 \%$ while achieving full four-level operation. More importantly, the higher available voltage allows extending the constant torque region of the motor, the further beginning of field weakening operation could be postponed.
\end{abstract}

Index Terms-Dual converter, more electric aircraft, multilevel converters, space vector modulation, voltage regulation

\section{INTRODUCTION}

A $\mathrm{S}$ to the push towards more electric aircraft (MEA) intensifies, aerospace systems are undergoing a transition from hydraulic, mechanical, and pneumatic power system into an integrated electric power system [1]-[3]. The MEA initiative can offer significant improvements in terms of the system efficiency and weight loss while reducing costs and emissions [4]-[6].

Considering this scenario, electromechanical actuators (EMAs) for flight control surface represent a key aspect of the MEA concept [7]. Indeed, on modern aircraft, EMAs are progressively replacing the bulky and more expensive hydraulic actuators in order to achieve higher reliability, flexibility and reduced weight [8], [9]. In Fig.1, the basic architecture of an EMA is depicted. The power converter feeds an electric machine, which is mechanically coupled to a step-down gearbox acting on the flight control surface pivot. Since the DC-link voltage is typically fixed for aerospace applications, the base speed of the electrical machine is limited

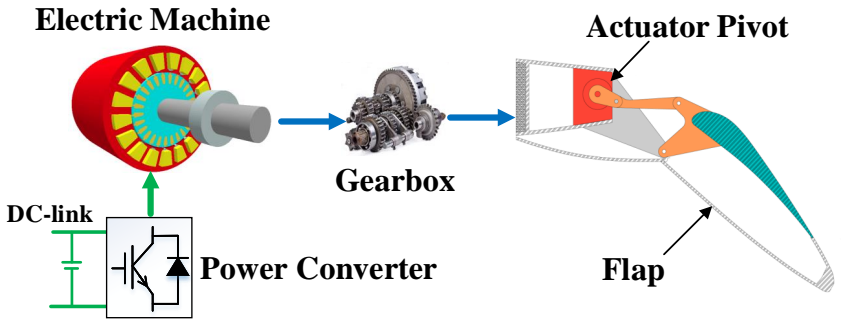

Fig. 1. EMA architecture for secondary flight surface

by the supplied voltage from power converter. For this reason, new power converter topologies as well as adapting advanced modulation schemes for increasing the voltage utilisation are being intensively investigated [1]-[3], [10], [11].

Multilevel converters are one of the most promising solutions for MEA drive applications due to their reduced dv/dt, better power quality and lower losses compared to traditional two-level converters. Many multilevel converter topologies have been developed and among them, the dual converter topology has received increasing attention for MEA applications. This mainly results from its redundancy [11], faulttolerance ability [12], [13] and the possibility of generating more voltage levels [14], [15]. The dual converter employs two standard two-level converters connecting to an openend winding machine [16], [17]. With the same number of switching devices of a three-level diode-clamped converter, the dual converter can achieve four-level voltages when the voltage ratio of two converters' supplies is 2:1. Apart from that, the dual converter has higher availability since it has 64 switching states while only 27 states can be generated by a three-level diode-clamped converter.

Generally, dual converters have three different configurations according to their power supply arrangement, i.e. the dual converter with two isolated voltage supplies (No.1), with a common DC-link (No.2), and with a DC-link and a floating bridge (No.3), as shown in Fig.2. The first configuration (No.1) is capable of multilevel operation but it needs a bulky transformer to achieve isolation [18], [19]. This would increase the volume and weight of system significantly, which is not desired in aerospace applications. The second configuration (No.2) has the highest degree of fault tolerance while it is suffered from zero-sequence current circulating [20]. In order 


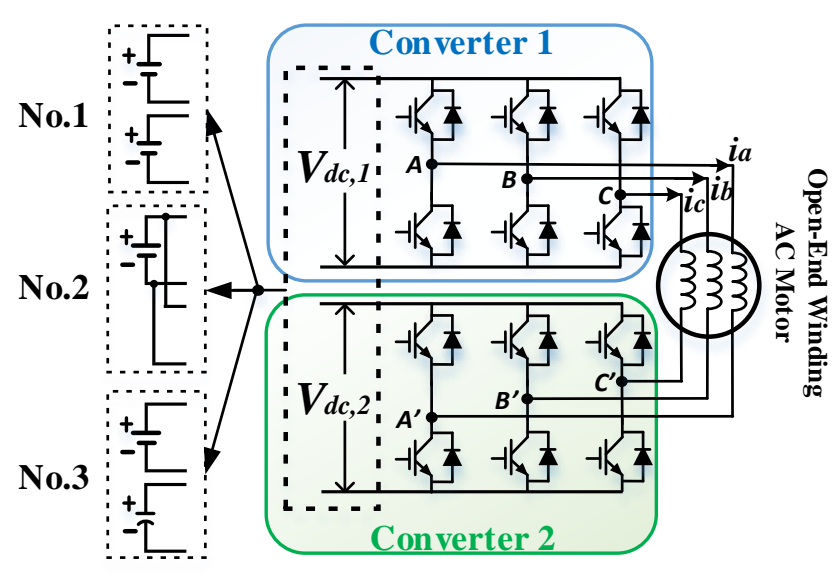

Fig. 2. Three configurations of dual converter topology

to suppress zero-sequence current, it may degrade from the multilevel to the two-level operation [14], [18], [19], [21]. The last configuration (No.3) comprises the merits of other two configurations in terms of multilevel output capability due to avoiding zero-sequence current circulation and no need of isolation circuitry since one bridge is floating. This paper will mainly focus on this configuration.

One major challenge of the chosen configuration is to regulate the floating capacitor's voltage to a desired value. In the past decades, various methods to regulate capacitor voltage have been proposed for multilevel converters, such as diodeclamped converters [1], [22], flying capacitor converters [23] and cascaded H-bridge converters [24], [25]. However, there is no comprehensive study regarding the voltage regulation methods for dual converters. In [18], [19], [26], [27], the dual converter is considered as a whole multilevel converter for modulation. The effect of switching states on capacitor voltage is analysed but the direction of phase current is ignored in [18]. More importantly, their analysis neglects the consideration of load power factor angle. The actual current acting on the floating capacitor would vary depending on the power factor angle [27]. According to conclusions in [18], [26], [27], due to the limitation of voltage regulation and achieving multilevel operation at the same time, the voltage utilisation of this dual converter configuration is constrained to the DC-link voltage. Under this condition, the capacitor voltage, which can be substantially beneficial for aerospace applications, is underutilised.

The other type of voltage regulation method for the chosen configuration is allocating active power flow and reactive power flow into the converter with a dc-link and the converter with a floating capacitor, respectively [28], [29]. The maximum floating capacitor voltage that can be regulated depending on power factor angle is defined in [28]. However, the main drawback of this method is causing undesirable voltage steps in the converter output. Due to the decoupled voltage control for two converters, the resulted voltage on load is unpredictable. These undesirable voltage steps would deteriorate output performance, which makes this configuration less attractive.

In this paper, the voltage regulation method of the dual

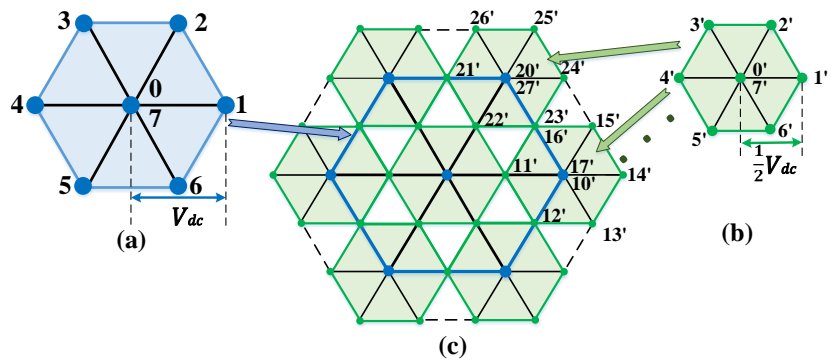

Fig. 3. Space Vector Diagram by (a): CON 1; (b): CON 2; (c): Resulted by dual converter

converter with a floating bridge is comprehensively studied for the first time. The instantaneous currents acting on the capacitor by all applicable switching states are analysed and the impact of load power factor is taken into consideration. Compared to previous voltage regulation methods, the proposed method can boost converter voltage utilisation by at least $10.1 \%$ and achieve multilevel operation at the same time. The paper will be organized as follows. The basic operation principle of dual converter is covered in Section II. In Section III, the effect of switching process on the voltage variation of floating capacitor is discussed. After that, the modulation scheme to regulate capacitor voltage along with its regulation capability is proposed in Section IV. The simulation and experimental results on an open-end winding induction motor as well as RL loads are displayed in Section $\mathrm{V}$ and Section VI, respectively. The potential benefits resulting from the application of the proposed method to an electric drive for EMA are finally investigated in Section VII. In particular, the advantages associated with the extension of the constant torque region due to the improved voltage utilization is analysed.

\section{PRinciple of Operation}

Considering the dual converter with a floating bridge of configuration 2 (No.2) in Fig.2, the voltage ratio $\left(V_{d c, 1} / V_{d c, 2}\right)$ of the two voltage sources is selected to be $2: 1$, in order to achieve a four-level operation. As shown in Fig.2, Converter 1 (CON 1) is supplied by a DC-link with a voltage of $V_{d c}$ and Converter 2 (CON 2) is powered by a floating capacitor at the voltage of $\frac{1}{2} V_{d c}$.

Fig. 3 shows the voltage vector diagram of a dual converter. One dot represents one switching vector in Fig. 3 and it can be expressed by several switching states, which are known as redundant states. For a two-level converter as shown in Fig.3 (a) and (b), the 8 switching states (0-7 or 0'-7') form 7 different vectors in the plane. Since the dual inverter employs two 2-level inverters, there are $8^{2}=64$ applicable switching states.

For the dual inverter, the phase voltage applied to the electrical loads is the voltage difference produced by the two converters (CON 1 in Fig.3 (a) and CON2 in Fig.3 (b)). The resulted space vector diagram in Fig.3 (c) can be drawn as small hexagons in Fig.3 (a) around vectors on the large hexagon in Fig.3 (b). The voltages applied to the supplied load thus can be represented with the switching states of both converters. For instance, switching state (15') represents 
Type I: $\left(23{ }^{\prime}\right)$

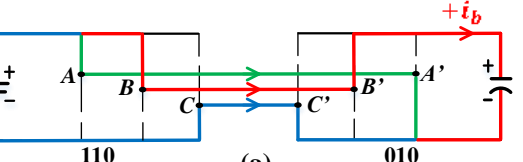

(a)
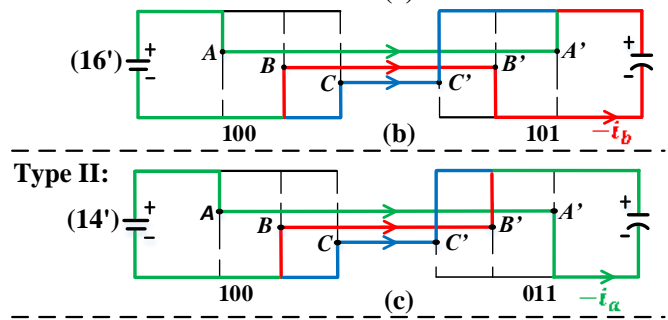

Type III:

$\left(27^{\prime}\right) \frac{+}{T-}$

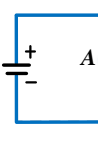

(c) $-011-i_{\underline{\alpha}}-$.

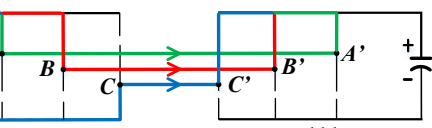

(d)

Fig. 4. Cases of different phase current act on floating capacitor

' 1 '(100) for CON 1 and ' 5 '(001) for CON 2. With the voltage ratio of $2: 1$, Fig.3 (c) demonstrates that this dual inverter produces 37 vectors from 64 switching states and the phase voltage applied to the electrical machine is a 4-level voltage.

\section{Effect of the SWitching Vector}

\section{A. Types of Switching Vector}

During the modulation process, the phase current $i_{a}, i_{b}$ and $i_{c}$ as shown in Fig.2 would charge or discharge the floating capacitor (FC) and result in a voltage variation. The 37 space vectors shown in Fig.3 (c) can be categorized into three different types: type I for the vector with redundancy states that make the phase current act on both the positive and negative polarity of the FC, type II for the vector only have either one case of current flow and type III for the vector has no effect on the voltage variation of FC.

These three types of space vector are demonstrated in Fig.4. The line colour in Fig.4 implies the flow path of different phase current. Green colour represents the path of current $i_{a}$, red indicates the path of current $i_{b}$ and blue shows the path of current $i_{c}$. In Fig.4 (a) and (b), the type I vector that has switching states (16') and (23') are shown. The current $i_{b}$ flows into the ' + ' polarity of FC in the case of (23') where flows into the '-' polarity of FC in the state of (16'). The former case is denoted as ' $+i_{b}$ ' whereas the latter one is represented by ' $-i_{b}$ '. This vector belongs to type I because it has redundancy states that could make phase current act on both the positive and negative polarity of the FC. In contrast, the vector with state (14') in Fig. 4 (c) is categorised into type II since it only could make the current $i_{a}$ act on the negative pole of FC. There is no current acting on the FC when the type III vector is applied, such as (27') in Fig. 4 (d). Under this condition, the FC voltage would remain constant.

Following this classification manner, 37 switching vectors of the dual inverter are denoted in sequence in Fig.5. The summary of three vector types I, II, III and their corresponding current flow into FC $I_{f c_{-} \text {typeI }}, I_{f c_{-} \text {typeII }}, I_{f c_{-} \text {typeIII }}$ are

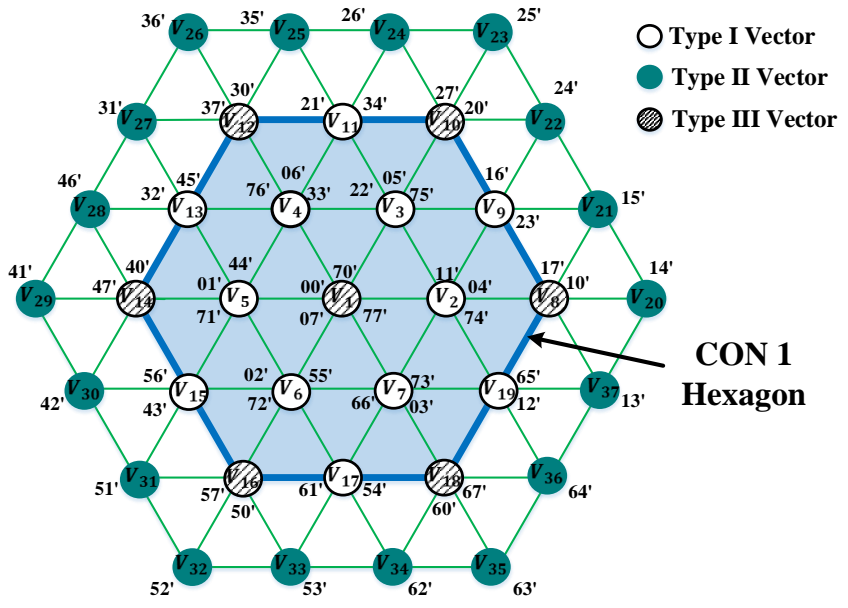

Fig. 5. Types of vector for the dual converter

detailed in Table I. The sign ' \pm ' means the phase current could act on both the positive and negative polarity of the FC.

\section{B. Phase Current Act on FC}

Within the hexagon of CON 1 in blue line in Fig.5, space vectors are associated with type I and III. The type III switching states are essentially the same ones of CON 1 . The type II vector locates on the outmost of vector diagram. In the following part, the current acting on the FC within CON1 hexagon and the area beyond that are discussed in sequence. Due to the symmetry of the three-phase system, the Sector I of space vector diagram by dual converter is considered, as displayed in Fig.6. Generally, the objective of converter modulation process is to synthesise the demand voltage vector $V_{r e f}$. The synthesis process is based on 'voltage-second balancing' principle, which can be expressed by (1), where $V_{0}, V_{1}, V_{2}$ are three applied space vectors and $d_{0}, d_{1}, d_{2}$ are their corresponding duty cycle of a switching period $T_{s}$, respectively. Additional, the definition of Modulation Index (M.I.) is given in (2), where $V_{d c \text {,overall }}$ refers to the sum of voltages of dual converter $V_{d c, 1}$ and $V_{d c, 2}$ in Fig.2.

$$
\begin{gathered}
V_{\text {ref }}=V_{0} * d_{0}+V_{1} * d_{1}+V_{2} * d_{2} \\
1=d_{0}+d_{1}+d_{2} \\
\text { M.I. }=\sqrt{3} * V_{\text {ref }} / V_{d c, \text { overall }}
\end{gathered}
$$

For the purpose of minimising output harmonic distortion, the nearest three vectors (NTV) method is adopted. For instance, if reference vector locates within region 2 in Fig. 6 (a), the nearest three vectors $V_{2}, V_{8}, V_{9}$ are applied in (1). In Fig.6 (a) of region 0-3, each has at least one type I vector and no existence of type II vector. The current flow to floating capacitor (FC) can be can be modelled as shown in (3), where the current $I_{f c_{-} t y p e I}$ can be found in the Table I and $d_{\text {typeI }}$, $d_{\text {typeIII }}$ are the duty cycle for type I and type III vector, respectively.

$$
\text { Region } 0-3: I_{f c}=d_{\text {typeI }} *( \pm) I_{f f_{-} \text {typeI }}+d_{\text {typeIII }} * 0
$$


TABLE I

CURRENT ACT ON THE FC BY THREE TYPES OF VECTOR

\begin{tabular}{c|ccc}
\hline \hline \multirow{2}{*}{ Sector } & I $\left(I_{f c_{-} t y p e I}\right)$ & Vector Type (current flow $\left.I_{f c}\right)$ & II $\left(I_{f c_{-} t y p e I I}\right)$ \\
& $V_{2}\left( \pm i_{a}\right), V_{3}\left( \pm i_{c}\right), V_{9}\left( \pm i_{b}\right)$ & $V_{20}\left(-i_{a}\right), V_{21}\left(+i_{c}\right), V_{22}\left(-i_{a}\right), V_{23}\left(+i_{c}\right)$ & $V_{1}(0), V_{8}(0), V_{10}(0)$ \\
\hline 1 & $V_{3}\left( \pm i_{c}\right), V_{4}\left( \pm i_{b}\right), V_{11}\left( \pm i_{a}\right)$ & $V_{23}\left(+i_{c}\right), V_{24}\left(-i_{b}\right), V_{25}\left(+i_{c}\right), V_{26}\left(-i_{b}\right)$ & $V_{1}(0), V_{10}(0), V_{12}(0)$ \\
3 & $V_{4}\left( \pm i_{b}\right), V_{5}\left( \pm i_{a}\right), V_{13}\left( \pm i_{c}\right)$ & $V_{26}\left(-i_{b}\right), V_{27}\left(+i_{a}\right), V_{28}\left(-i_{b}\right), V_{29}\left(+i_{a}\right)$ & $V_{1}(0), V_{12}(0), V_{14}(0)$ \\
4 & $V_{5}\left( \pm i_{a}\right), V_{6}\left( \pm i_{c}\right), V_{15}\left( \pm i_{b}\right)$ & $V_{29}\left(+i_{a}\right), V_{30}\left(-i_{c}\right), V_{31}\left(+i_{a}\right), V_{32}\left(-i_{c}\right)$ & $V_{1}(0), V_{14}(0), V_{16}(0)$ \\
5 & $V_{6}\left( \pm i_{c}\right), V_{7}\left( \pm i_{b}\right), V_{17}\left( \pm i_{a}\right)$ & $V_{32}\left(-i_{c}\right), V_{33}\left(+i_{b}\right), V_{34}\left(-i_{c}\right), V_{35}\left(+i_{b}\right)$ & $V_{1}(0), V_{16}(0), V_{18}(0)$ \\
6 & $V_{7}\left( \pm i_{b}\right), V_{8}\left( \pm i_{a}\right), V_{19}\left( \pm i_{c}\right)$ & $V_{35}\left(+i_{b}\right), V_{36}\left(-i_{a}\right), V_{37}\left(+i_{b}\right), V_{20}\left(-i_{a}\right)$ & $V_{1}(0), V_{18}(0), V_{8}(0)$ \\
\hline \hline
\end{tabular}

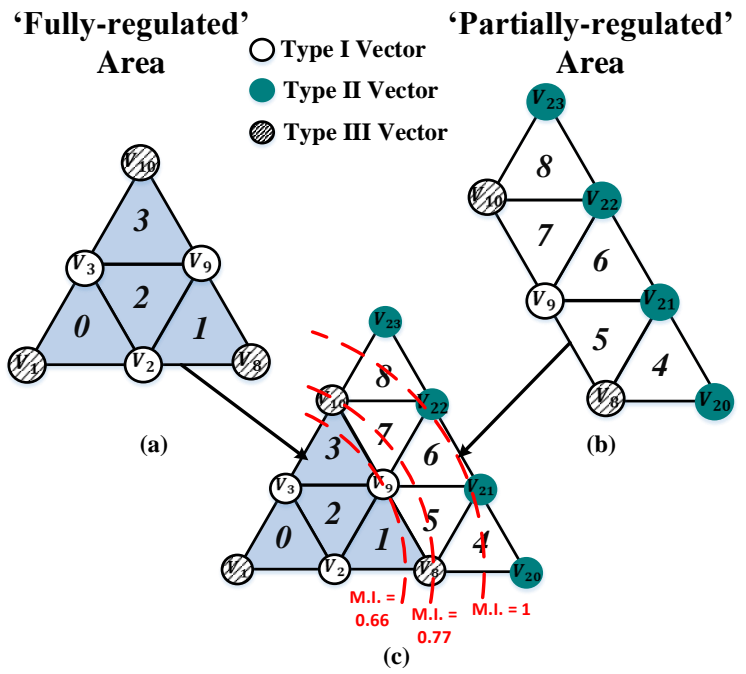

Fig. 6. Space vector diagram within a) 'Fully-regulated Area' of Sector I; b) 'Partially-regulated Area' of Sector I; c) Section I

From (3), it is obvious that the sign of current flow into FC can be selected flexibly thus the area in Fig.6 (a) is called 'Fully-regulated Area'. If the reference vector operates beyond the CON 1 hexagon in Fig.5, the type II vector is unavoidably involved. In Fig.6 (b), there are at least one type II vector in each region and even absence of type I vector for region 4 and 8. For this case, the current flow to floating capacitor (FC) can be modelled by (4) and (5), where current $I_{f c_{-} \text {typeII }}$ can be found in the Table I and $d_{\text {typeII }}$ is the duty cycle for type II vector.

Region $5-7: I_{f c}=d_{\text {typeI }} *( \pm) I_{f c \_t y p e I}+d_{\text {typeII }} * I_{f c \_t y p e I I}$

$$
\text { Region4, } 8: I_{f c}=d_{\text {typeII }} * I_{f c_{-} \text {typeII }}
$$

From (4) and (5), it can be deduced that due to the existence of type II vector, then the current act on the FC cannot be completely manipulated, especially for region 4 and 8 in (5). Therefore, the area in Fig.6 (b) is denoted as 'Partiallyregulated Area'.

\section{Charge Variation of FC}

When a switching state (mn') is applied, the variation of FC voltage $\Delta V_{f c_{\_} m n^{\prime}}$ and charge $\Delta Q_{f c_{-} m n^{\prime}}$ can be represented, where $\mathrm{C}$ is the capacitance of $\mathrm{FC}$ and $T_{m n^{\prime}}$ is the switching time of state (mn').

$$
\Delta Q_{f c_{-} m n^{\prime}}=C * \Delta V_{f c_{\_} m n^{\prime}}=\int_{0}^{T_{m n^{\prime}}} I_{f c}(\text { sector }) d t
$$

Accordingly, the charge variation of FC by three types of vector $\Delta Q_{f c_{-} \text {typeI }}, \Delta Q_{f c_{-} \text {typeII }}, \Delta Q_{f c_{-} t y p e I I I}$ can be expressed by (7) where $T_{\text {typeI }}\left(=d_{\text {typeI }} * T_{s}\right), T_{\text {typeII }}(=$ $\left.d_{\text {typeII }} * T_{s}\right)$ are the switching time for type I and type II vector, respectively.

$$
\begin{gathered}
\Delta Q_{f c_{-} \text {typeI }}=\int_{0}^{T_{\text {typeI }}} I_{f c_{-} \text {typeI }}(\text { sector }) d t \\
\Delta Q_{f c_{-} \text {typeII }}=\int_{0}^{T_{\text {typeII }}} I_{f c_{-} \text {typeII }}(\text { sector }) d t \\
\Delta Q_{f c_{-} \text {typeIII }}=0
\end{gathered}
$$

Recent research related to the dual converter only considered the movement of reference vector within the 'Fullyregulated Area' [18], [26], [27]. This refers to the CON 1 hexagon in Fig.5, which means only the main DC-link voltage, $66 \%$ of the overall voltage, is utilised. It cannot be denied that the regulation capability is constrained within 'Partiallyregulated Area'. In particular, an active modulation scheme that requires the feedback of phase current is necessary.

\section{Proposed Voltage Regulation Method}

\section{A. Working Principle}

Regarding 'Fully-regulated Area', the voltage of FC could be fully regulated since the sign of current flow into FC can be chosen according to the regulation need. The required charge to balance capacitor voltage is represented by ' $Q_{r e q}$ ' in (8) when reference vector locates within 'Fully-regulated Area' and where $V_{f c}, V_{f c, r e f}$ is the FC voltage and the reference FC voltage, respectively. 


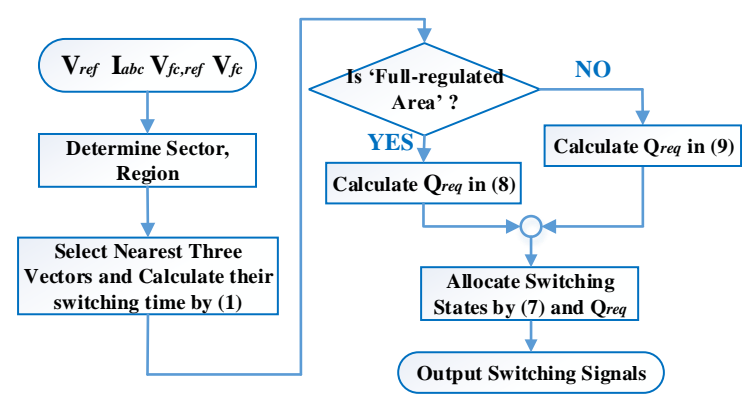

Fig. 7. Flowchart of proposed regulation method

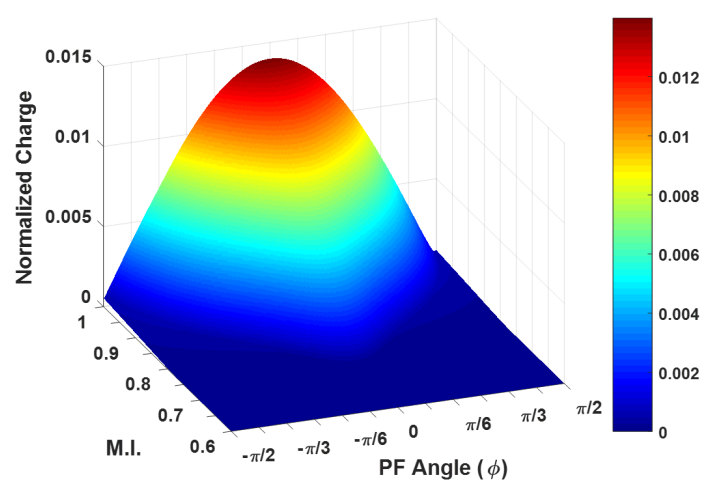

Fig. 8. Maximum Charge variation of FC over a switching period

$$
Q_{r e q}=C *\left(V_{f c}-V_{f c, r e f}\right)
$$

Therefore, the switching states' allocation of type I vector can be determined based on (7) and (8). Once the reference vector enters 'Partially-regulated Area', the type II vector is involved and its charge variation on FC can be calculated by (7). Then, in this case, $Q_{r e q}$ can be expressed by (9).

$$
Q_{r e q}=C *\left(V_{f c}-V_{f c, r e f}\right)+\int_{0}^{T_{t y p e I I}} I_{f c_{-} \text {typeII }}(\text { sector }) d t
$$

In summary, the proposed FC voltage regulation mechanism can be demonstrated by the flowchart shown in Fig.7. Initially, the nearest three vectors (NTV) and their switching time are obtained after the sector and region of $V_{\text {ref }}$ is determined. The required charge ' $Q_{\text {req }}$ ' can be calculated by (8) or (9) depending on the $V_{r e f}$ is in 'Fully-regulated Area' or 'Partially-regulated Area'. Based on the overall consideration of corresponding current flow in Table I with the information of current $I_{a b c}$, the switching states of type I vector can be allocated by (7) to compensate the $Q_{r e q}$. Finally, the switching signals for dual inverter can be generated.

\section{B. Resulted Charge Variation of FC}

Following the proposed modulation method depicted in Fig.7, the maximum charge variation over a switching period by the proposed method is showed in Fig.8. The x-axis is the modulation index (M.I.) from 0.6 to 1 and $y$-axis is power factor (PF) angle from $-\pi / 2$ to $\pi / 2$.

The charge is normalised by the phase current amplitude. In Fig.8, it can be observed that the charge variation on FC is generally low at lower modulation indexes region and large at higher modulation indexes region. In particular, the charge variation of FC over a switching period is zero when M.I. is smaller than 0.66 , which is denoted as 'Fully-regulated area' in Fig.6. Additionally, the charge variation is relatively large when power angle is around 0 , i.e. power factor is 1 , whereas relatively small when power angle is around $-\pi / 2$ and $\pi / 2$, i.e. power factor is 0 . In summary, the allowable modulation index may be increased when power factor decreases.

\section{Voltage Utilisation Boundary}

As mentioned above, manipulating two redundant switching states of type I vector defines the voltage regulation capability. When the reference vector enters 'Partially-regulated Area', the type II vector is introduced. The voltage regulation boundary of the proposed method is determined by the comparison of the absolute value of resulted charge by type I vector $\left|Q_{f c_{-} \text {typeI }}\right|$ and by type II vector $\left|Q_{f c_{-} \text {typeII }}\right|$ over a fundamental cycle of the reference vector $V_{r e f}$, as shown in below:

$$
\begin{gathered}
\left|Q_{f c_{\_} \text {typeI }}\right|=\sum \int_{0}^{2 \pi} \mid \int_{0}^{T_{\text {typeI }}} I_{f c_{-} \text {typeI }}(\text { sector }) d t \mid d \theta \\
\left|Q_{f c_{\_} \text {typeII } I}\right|=\mid \sum \int_{0}^{2 \pi}\left(\int_{0}^{T_{\text {typeII }}} I_{f c_{-} \text {typeII }}(\text { sector }) d t\right) d \theta \mid
\end{gathered}
$$

For a certain modulation index (M.I.) and a power factor (PF) angle, if $\left|Q_{f_{-} c_{\text {typeI }}}\right|$ is larger than $\left|Q_{f_{-} c_{\text {typeII }}}\right|$, this means the charge caused by type II vector can be fully compensated by the charge resulted from type I vector over a fundamental cycle. In this case, the voltage level of FC can be maintained. Otherwise, if $\left|Q_{f c_{-} \text {typeI }}\right|$ is smaller than $\left|Q_{f_{-} \text {typeII }}\right|$, the FC voltage could not be regulated. For instance, when M.I. is between 0.66 and 0.77 as shown in Fig.6 (c), the reference vector would pass by Region 1, 5, 6, 7,3 of Sector I in sequence. Therefore, the involved vectors are $V_{2}, V_{9}, V_{3}$ of type I vector and $V_{21}, V_{22}$ of type II vector. Their resulted charges on the FC over Sector I could be derived by (11) where $\theta$ is the angle of reference vector. The switching time $T_{V_{2}}, T_{V_{9}}, T_{V_{3}}, T_{V_{21}}, T_{V_{22}}$ are simply obtained by multiplying their corresponding duty cycles through (1) by a switching period $T_{s}$. 


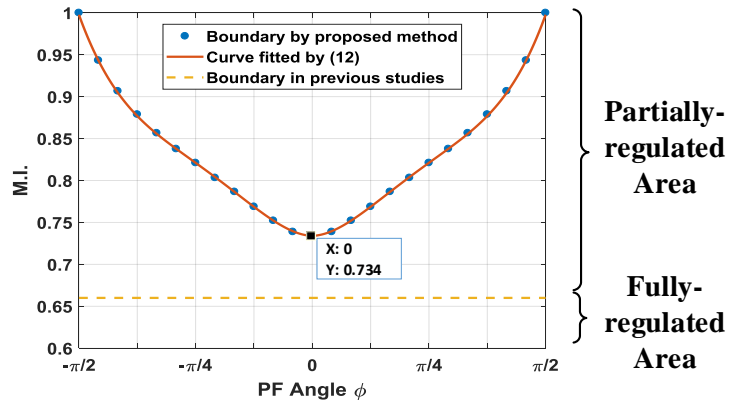

Fig. 9. The controllable area of $\mathrm{FC}$ voltage verse power factor angle

$$
\begin{gathered}
\left|Q_{f c \_t y p e I}\right|=\int_{0}^{\frac{\pi}{3}}\left|\int_{0}^{T_{V_{2}}} i_{a} d t\right| d \theta+\int_{0}^{\frac{\pi}{3}}\left|\int_{0}^{T_{V_{9}}} i_{b} d t\right| d \theta+ \\
\int_{0}^{\frac{\pi}{3}}\left|\int_{0}^{T_{V_{3}}} i_{c} d t\right| d \theta \\
\left|Q_{f c \_t \text { typeII }}\right|=\left|\int_{0}^{\frac{\pi}{3}}\left(\int_{0}^{T_{V_{21}}} i_{c} d t\right) d \theta+\int_{0}^{\frac{\pi}{3}}\left(\int_{0}^{T_{V_{22}}}-i_{a} d t\right) d \theta\right|
\end{gathered}
$$

Fig.9 displays the boundary between allowable M.I. and PF angle $(\phi)$ by the proposed voltage regulation method in the blue dots. In particular, the minimum value of 0.734 is occurred at the PF angle of 0 since $\left|Q_{f_{c_{-}} \text {typeII }}\right|$ would exceed $\left|Q_{\text {f__typeI }}\right|$ once the M.I. increases beyond that threshold value. In addition, the red curve displays that the analytical boundary is fitted by using 'curve fitting' toolbox inside Matlab. The fitted equation can be written as:

$$
\begin{array}{r}
\text { M.I. }(\phi)=0.133 *|\phi|-0.353 *(|\phi|)^{2}+0.33 *(|\phi|)^{3}+ \\
0.005 *(|\phi|)^{4}+0.734
\end{array}
$$

Equation (12) provides a mathematical approach to derive the maximum voltage utilisation according to load PF factor. Regarding previous studies, the voltage utilisation of the dual converter with a floating bridge is constrained as $66 \%$ of the overall voltage. In contrast, as shown in Fig.9, the minimum M.I. by the proposed method is 0.734 at $0 \mathrm{PF}$ angle (unity PF) and the maximum value is 1 at $\pm \pi / 2 \mathrm{PF}$ angle (zero PF). This means the voltage utilisation of this topology can be increased by at least $10.1 \%$. Additionally, the method proposed in [18] is considered as the 'benchmark method' and would be chosen to compare with the proposed method in the following.

\section{Simulation Results}

A simulation model of motor drive system with dual converter for aerospace applications is built within PLECS (standalone) environment. The detailed parameters of induction machine and power converter are shown in Table II. The deadtime is selected since it is the minimum value allowed
TABLE II

MACHINE AND Converter PARAMETERS

\begin{tabular}{cc|cc}
\hline \hline \multicolumn{2}{c|}{ Power Converter } & & \multicolumn{2}{c}{ Induction Motor } \\
\hline Main DC-link voltage & $540 \mathrm{~V}$ & Stator resistance & $1.2 \Omega$ \\
FC voltage & $270 \mathrm{~V}$ & Rotor resistance & $1.01 \Omega$ \\
Main DC-link capacitance & $1250 \mu \mathrm{F}$ & Rated current (RMS) & $14.23 \mathrm{~A}$ \\
FC Capacitance & $3250 \mu \mathrm{F}$ & Power factor (at full load) & 0.80 \\
Switching frequency & $5 \mathrm{kHz}$ & No-load current (RMS) & $5.77 \mathrm{~A}$ \\
Deadtime & $4.1 \mu \mathrm{s}$ & Power factor (at no load) & 0.03 \\
\hline
\end{tabular}

by the power converters employed in the practical experiment. In order to minimize the potential affect of deadtime on the modulation process and FC charging and discharging, the switching frequency of $5 \mathrm{kHz}$ is chosen thus deadtime only occupies approximately $2 \%$ of one switching cycle (i.e. $200 \mu$ s). The system performance by the proposed modulation scheme and the benchmark method are simulated and compared. A guideline of FC sizing for a given voltage ripple requirement is presented.

\section{A. Control Schematic}

Fig.10 depicts the closed-loop control schematic of an open-end drive system. This system consists of the main converter (CON 1) supplied by a DC-link, sub converter (CON 2) supplied by an FC, and an open-end winding induction machine connected mechanically with a DC machine through a shaft. The elegant field orientation control is applied where 'Nested loop' of outer speed and flux control with inner current control loop is adopted. The speed control loop is designed for minimizing the speed error and it provides the reference value of stator q-axis current $I_{s q}^{*}$, which represents one of the two inputs of the q-axis current controller ('Inner Current Control' in Fig.10). The q-axis current controller is a proportional-integral (PI) controller that generates the stator qaxis reference voltage $V_{s q}^{*}$. Considering the flux control loop (i.e. 'Outer Flux Control' of Fig.10), its output consists in the reference d-axis current $I_{s d}^{*}$, which is applied as input to the d-axis current controller ('Inner Current Control' in Fig.10). The latter provides the output of stator d-axis voltage reference $V_{s d}^{*}$. Both the voltage reference signals in the rotating $d q$ frame (i.e. $V_{s q}^{*}$ and $V_{s d}^{*}$ ) are referred in the stationary $\alpha \beta$ reference frame using the stator flux electric angle $\theta_{e}$. Hence, the reference voltage vector $V_{\text {ref }}$ is generated at the output of the coordinate transformation block and it is employed by the SVM modulator for modulation purpose.

The SVM modulator in grey colour in Fig.10 is the core part of whole control system. It take the responsibilities of modulating reference vector and achieving voltage regulation of FC at the same time. The switching vectors are derived from the modulation process and switching states are allocated according to the need of regulating FC voltage, as described in Fig.7.

In Fig.11, the performance of dual converter drive system using the proposed method in blue colour and the benchmark method in red colour is demonstrated for comparison. The simulation condition is to give a step speed reference 


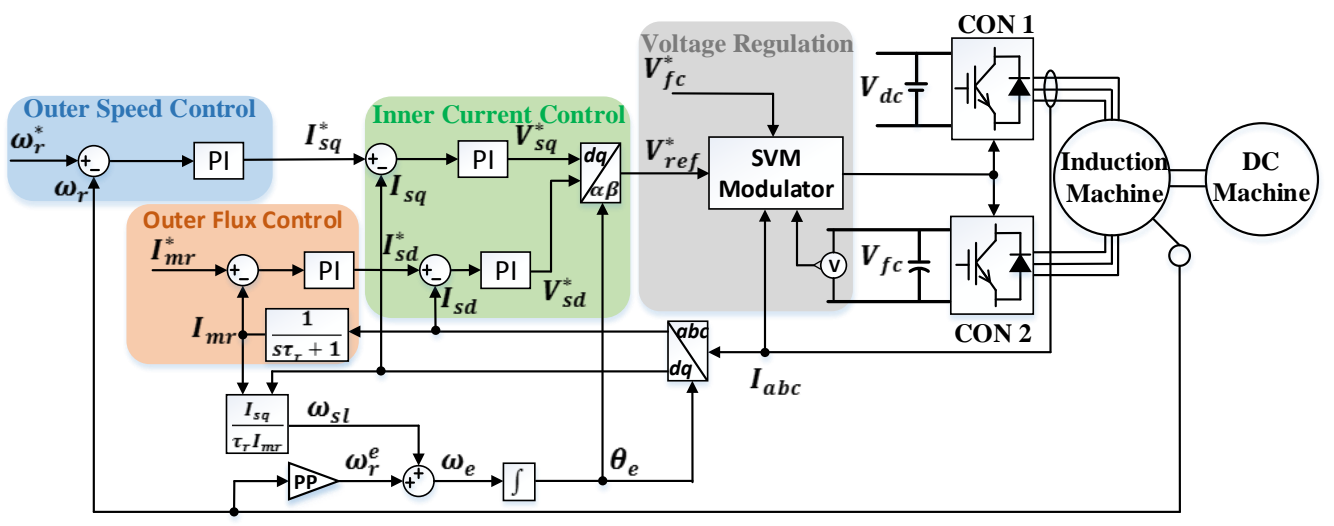

Fig. 10. Control schematic of the motor drive system

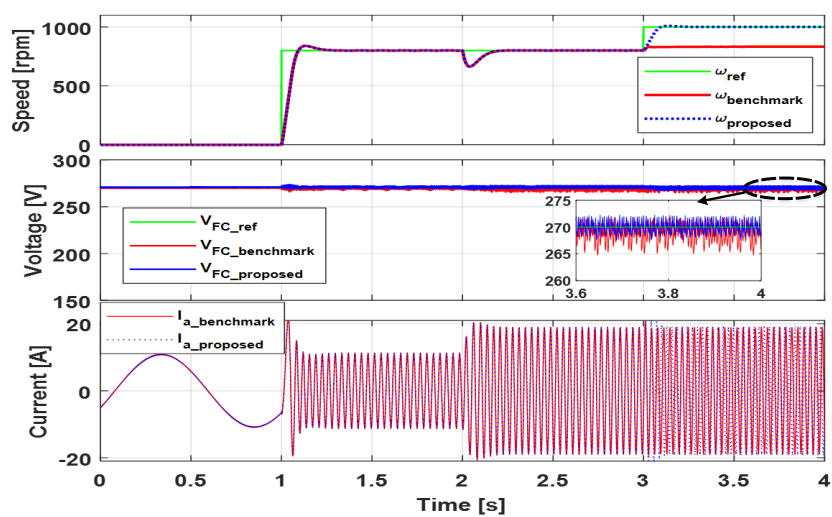

Fig. 11. Simulated drive performance comparison at $72 \mathrm{~N}^{*} \mathrm{~m}$ load torque

$\omega_{\text {ref }}=800 \mathrm{rpm}$ at $1 \mathrm{~s}$, and a step load torque $T_{L}=72 \mathrm{~N}^{*} \mathrm{~m}$ at 2s. In the first subplot of Fig.11, it displays that the speed performance is nearly matched by two methods before $2 \mathrm{~s}$. After that, the speed reference $\omega_{\text {ref }}$ is increased to 1000rpm at $3 \mathrm{~s}$. The drive system by the proposed method can follow the speed while by the benchmark method could not. Since speed is proportional to the supplied voltage, this validates that the proposed method can boost voltage utilisation compared to using the benchmark method. Regarding FC voltage in the second subplot of Fig.11, the proposed method shows superior performance over the benchmark method in terms of more accurate and stable voltage regulation of FC. The mean value of FC voltage is $269.90 \mathrm{~V}$ and the peak-to-peak ripple is $4.68 \mathrm{~V}$. In contrast, mean value of FC voltage and the peak-to-peak ripple is $268.32 \mathrm{~V}$ and $7.25 \mathrm{~V}$ by the benchmark method, respectively. Due to superior performance of voltage regulation, the current THD (total harmonic distortion) using the proposed method is $3.2 \%$, which is improved slightly compared to $3.4 \%$ by using the benchmark method as shown in the third subplot of Fig.11.

\section{B. Sizing of FC}

If the amplitude of phase current $I_{\text {phase }}$ is known, the size of floating capacitor (FC) ' $C_{r e q}$ ' can be derived by (13) for a given voltage ripple requirement $\Delta V_{\max }$. One essential item in

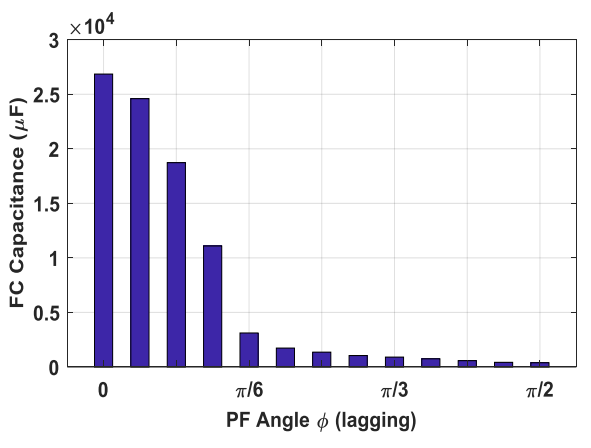

Fig. 12. Recommended capacitance size for a specified voltage ripple demand

this equation is the normalised charge variation $Q_{\text {norm }}$, which can be found in Fig.8.

$$
\Delta C_{\text {req }}=\frac{Q_{\text {norm }} * I_{\text {phase }}}{V_{\max }}
$$

Equation (13) should provide sufficient guidelines to size the FC when the desired voltage requirement and operation condition is informed. For instance, the peak-to-peak voltage ripple requirement is set to $2 \%$ of $\mathrm{FC}$ voltage, which is $5.4 \mathrm{~V}$ for $270 \mathrm{~V}$. If the modulation index is 0.76 and the maximum current $I_{\text {phase }}$ is $20.1 \mathrm{~A}$, the recommended FC sizing $C_{r e q}$ is depicted in Fig.12. For a fully-loaded machine with load power factor of 0.80 as indicated in Table II, the capacitor capacitance should be chosen at least $3022 \mu \mathrm{F}$. The chosen capacitance in the simulation as well as experiment is $3250 \mu \mathrm{F}$ as indicated in Table II, which is slightly larger than $3022 \mu F$. From the third subplot of Fig.11, the peak-to-peak ripple of FC is $4.68 \mathrm{~V}$ that accounts for $1.73 \%$ of $270 \mathrm{~V}$. This result meets the requirement of $2 \% \mathrm{FC}$ voltage.

\section{EXPERIMENTAL REsults}

In this section, the motor drive prototype as shown in Fig.13 is carried out in the real experiment. The converter voltage utilisation and FC performance by the proposed method and the benchmark method are compared. In particular, the analytical relationship of converter voltage utilisation verse load power 


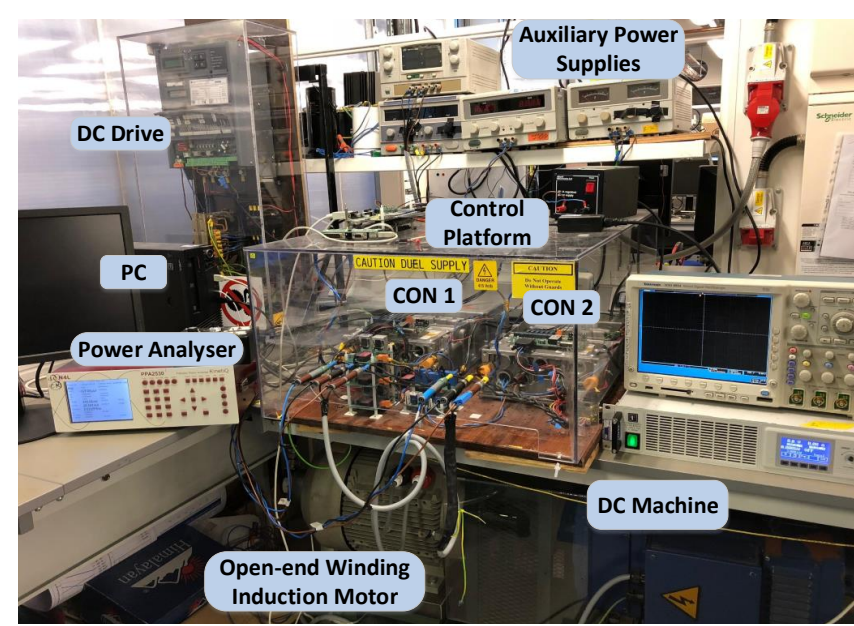

Fig. 13. Experimental rig setup

factor angle in Fig.9 is tested. Since the power factor (PF) of induction machine is relatively low, the validation experiment for high PF condition is conducted by a series of RL loads.

In Fig.13, the chosen power converters are 'off-the-shelf' two-level converters produced by SEMIKRON. These converters have integrated gate drivers with DC-side capacitor of $1250 \mu \mathrm{F}$ capacitance, RC snubber, and input-output common mode choke. Additionally, the DC-side of converter is paralleled with Y-capacitor in order to suppress EMI. The control platform consists of a Digital Signal Processor (DSP) and a field-programmable gate array (FPGA) board. The DC machine is connected mechanically to the open-end winding induction motor to act as a load. It is operated under torque control using an industrial DC drive, thus variable load torque on the induction motor is applicable. The power analyser N4LPPA2530 is applied to measure the load power factor angle.

\section{A. Performance Comparison}

In Fig.14, the motor drive performance comparison by the proposed method and the benchmark method are displayed. The test condition is setting reference speed to $800 \mathrm{rpm}$ then increasing to $1000 \mathrm{rpm}$ at $1 \mathrm{~s}$. In the first subplot of Fig.14, after $1 \mathrm{~s}$, the drive system by the proposed method in red line still can follow reference speed in green line but the drive system by the benchmark method in blue line could not. The reason is revealed in the second subplot of Fig.14. The speed reference of $1000 \mathrm{rpm}$ requires higher voltage supply than $66 \%$ of the overall voltage. This validates that the proposed modulation method can boost converter voltage to supply on the electric loads. In the third subplot of Fig.14, the measured FC voltage by the benchmark method in blue colour has a peak-to-peak ripple of $8.6 \mathrm{~V}$ and the average value is around $266.7 \mathrm{~V}$. It is obvious that the proposed modulation scheme in red colour presents superior FC voltage regulation performance with $4.3 \mathrm{~V}$ ripple and the mean value of $270.0 \mathrm{~V}$ approximately. This indicates the size of the FC could be smaller for a given voltage ripple requirement if the proposed modulation scheme is applied, which agrees with the results in the simulation.

In addition, another experimental comparison is carried out by adopting lower capacitance of FC (i.e. $1250 \mu \mathrm{F}$ ). Besides

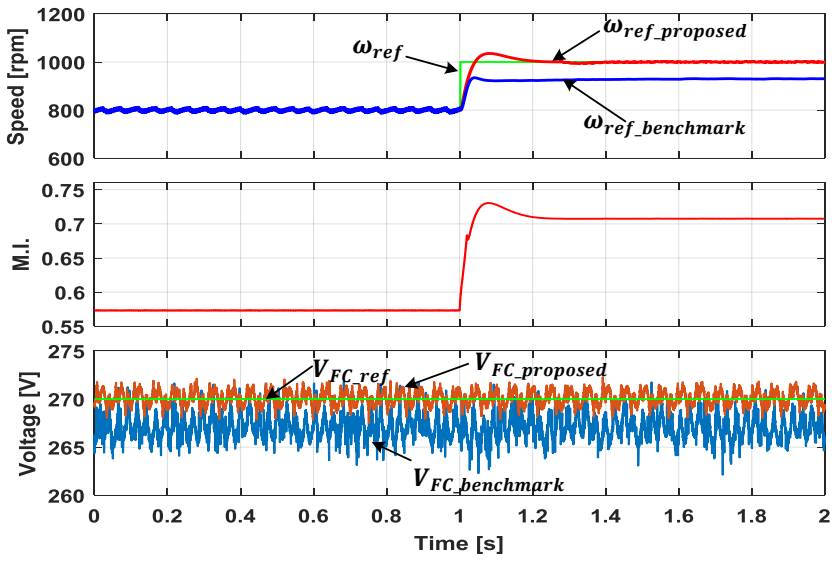

Fig. 14. Experimental drive performance comparison when $\mathrm{PF}$ factor $=$ 0.5 and the capacitance of $\mathrm{FC}$ is $3250 \mu \mathrm{F}$

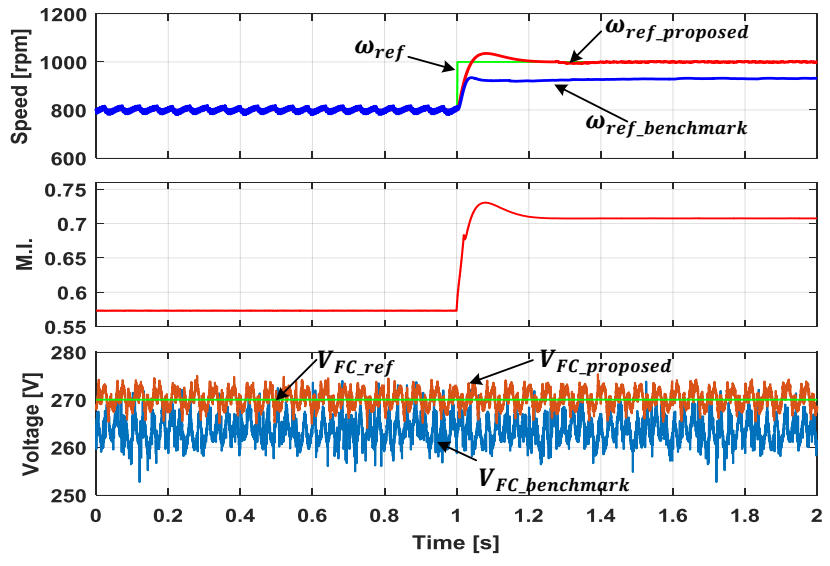

Fig. 15. Experimental drive performance comparison when $\mathrm{PF}$ factor $=$ 0.5 and the capacitance of $\mathrm{FC}$ is $1250 \mu \mathrm{F}$

that, the test conditions maintain the same as previous. Compared to Fig.14, peak-to-peak ripples of FC voltage in Fig.15 have significantly increased. The measured FC voltage by the benchmark method has a peak-to-peak ripple of $19.8 \mathrm{~V}$ and the average value is around $262.4 \mathrm{~V}$. In contrast, the proposed modulation scheme still presents superior $\mathrm{FC}$ voltage regulation performance with $9.9 \mathrm{~V}$ ripple and the mean value of $269.8 \mathrm{~V}$ approximately.

\section{B. Boundary Validation}

In order to validate the analytical voltage regulation capability under specific power factor, an open-loop V/f control is adopted. During test, the magnitude of voltage reference is increased gradually. When the FC voltage starts to reduce below the reference value, this means that the maximum allowed modulation index was achieved. Fig.16 displays results when the induction motor is operated under no load where RMS of phase current is 5.77A. The experimental results for a fully-loaded induction motor with phase current of 14.23A (RMS) are reported in Fig. 17. These two load conditions are corresponded to load power factor of 0.03 and 0.80 as shown in Table II, respectively. 


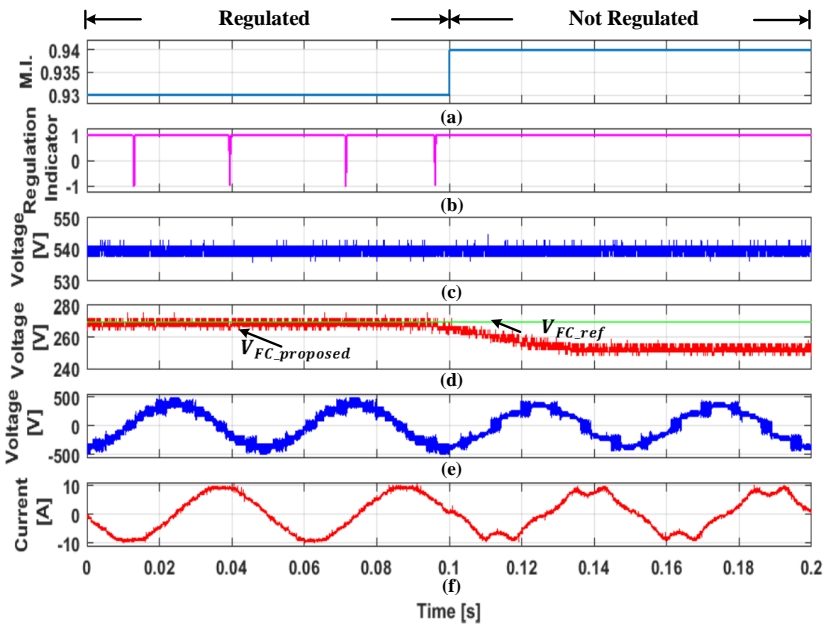

Fig. 16. Motor drive performance a) M.I; b) Regulation indicator; c) DClink voltage; d) FC voltage; e) Phase voltage; f) Phase current when PF $=0.03$

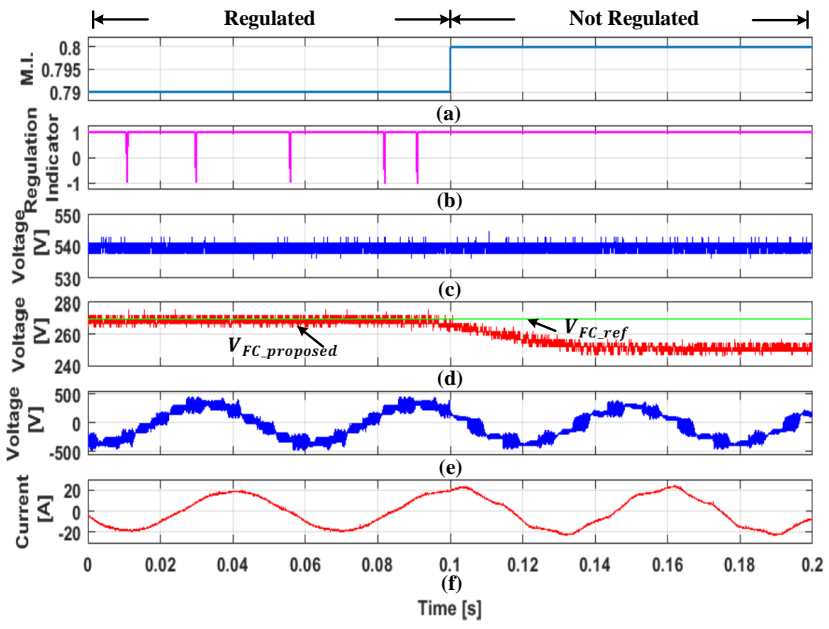

Fig. 17. Motor drive performance a) M.I; b) Regulation indicator; c) DC link voltage; d) FC voltage; e) Phase voltage; f) Phase current when PF $=0.80$

In Fig.16 (a), the dual inverter works at 0.93 modulation index (M.I.) from 0 to $0.1 \mathrm{~s}$ and then it is increased to 0.94 at $0.1 \mathrm{~s}$. The regulation indicator is referred to ' $Q_{r e q}$ ' in (8) and (9). It displays ' 1 ' as ' $Q_{r e q}<0$ ' while ' -1 ' if ' $Q_{r e q}>0$ '. During $0-0.1 \mathrm{~s}$, the regulation indicator in Fig.16 (b) is ' 1 ' for the most of time duration while '-1' for small portion of time duration. This means the capability of capacitor voltage regulation closes to its limitation. The Fig.16 (d) indicates the voltage of floating capacitor can be regulated around reference value $(270 \mathrm{~V})$ at M.I. $=0.93$. In addition, the phase voltage in Fig.16 (e) has distinct 7-level, which is characteristic of expected 4-level inverter performance. However, when M.I. rises up to 0.94 , the regulation indicator is ' 1 ' constantly which means the dual inverter has operated beyond its regulation capability. As expected, the capacitor voltage is decreasing below the level of reference voltage. Consequently, undesired phase voltage steps and distorted phase current waveform can be demonstrated in Fig.16 (e) and (f), respectively. Regarding the fully-loaded induction motor, the experiment follows the

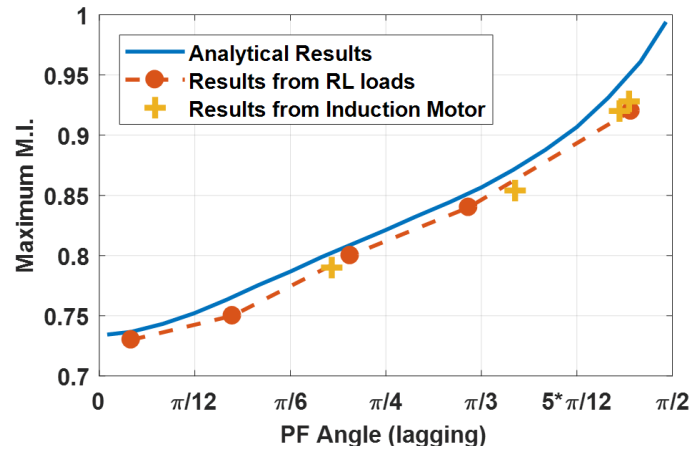

Fig. 18. Comparison of voltage capability results

TABLE III

THE BASE SPEED COMPARISON

\begin{tabular}{l|cc|cc}
\hline \hline \multirow{2}{*}{ Load Condition } & \multicolumn{2}{|c|}{ The Benchmark Method } & \multicolumn{2}{c}{ The Proposed Method } \\
& Max. M.I. & Base Speed & Max. M.I. & Base Speed / (boosted) \\
\hline No load & 0.66 & $987 \mathrm{rpm}$ & 0.96 & $1434 \mathrm{rpm} /(45.3 \%)$ \\
Fully load & 0.66 & $839 \mathrm{rpm}$ & 0.79 & $1018 \mathrm{rpm} /(21.3 \%)$ \\
\hline \hline
\end{tabular}

same manner as for no-load test. Fig.17 display the maximum modulation index of inverter is 0.79 at the load power factor of 0.80 .

In Fig.18, the results of voltage utilisation verse load power factor from experimental results are recorded and compared with outcomes in the analytical study. The experimental results are slightly smaller than the analytical boundary of voltage regulation capability, but these two outcomes agree generally. This mismatch may result from dead-time thus a more advanced dead-time compensation is worthy to develop in the further studies.

\section{IMPLEMENTATIONS OF THE PROPOSED METHOD ON AN EMA ELECTRIC DRIVE}

As previously highlighted, one of the key benefits arising from the adoption of the proposed method consists in a better utilization of the available DC-link voltage. This advantage can be exploited in EMA aerospace applications where the DC-link voltage is fixed and field weakening operations are often required for motors [30]. This indicates that they need to operate beyond the base speed, which is related to the voltage supplied by power converter. The higher available voltage resulting from the employment of the proposed method allows extending the torque constant region of the motor (i.e. higher value of base speed). Thus, the beginning of the field weakening operations is postponed and the rated torque can be developed on a wider range of speed.

In Table III, the comparison between the benchmark and the proposed methods is reported in terms of base speed improvement for the machine under test. The base speed refers to the maximum speed that machine could operate without reducing the field current $\left(i_{d}\right)$. As shown in Table III, the maximum modulation index of dual converter is 0.66 by the benchmark method, despite the load condition. In contrast, the proposed method can make the dual converter to 
supply $96 \%$ and $79 \%$ of the overall voltage when the machine works at no-load and fully-load condition, respectively. This significant enhancement of the voltage utilisation reflects on the machine's base speed. For a no-load machine, the base speed can be boosted by $45.3 \%$ if the proposed modulation scheme is utilised. In addition, the improvement percentage of base speed is $21.3 \%$ for a fully-loaded machine, as indicated in Table III. This boosted base speed could allow the machine to minimize its weight and volume considerately, which is critical for aerospace applications.

\section{CONCLUSION}

In this paper, the dual converter with a floating bridge for aerospace applications is studied and an implementation instance of flight surface control on MEA is given. In order to regulate the voltage of $\mathrm{FC}$, the instantaneous current that acts on the FC is analysed. After a quantified modelling of charge variation of FC by switching states, an active space vector modulation scheme with current feedback is proposed. In particular, the capability of regulating the floating capacitor voltage is defined and a fitted polynomial equation is derived to express this relationship. Compared to the benchmark method that previously presented, benefits of the proposed modulation scheme that have been validated in both simulation and experiment include:

1) Superior FC voltage regulation performance in term of more accurate average value and less voltage ripple;

2) Boosted base speed for electric machines with a fixed DC link voltage;

3) Boosted voltage utilisation of converter by at least $10.1 \%$ and achieving four-level operation;

Using this modulation scheme, the advantages of dual inverter with a floating bridge can be fully exploited and make it more competitive among other multilevel inverter topologies for aerospace applications.

\section{REFERENCES}

[1] C. Li, T. Yang, P. Kulsangcharoen, G. L. Calzo, S. Bozhko, C. Gerada and P. Wheeler, "A modified neutral-point balancing space vector modulation technique for three-level neutral point clamped converters in high speed drives," IEEE Transactions on Industrial Electronics, 2018.

[2] S. Roggia, F. Cupertino, C. Gerada, and M. Galea, "A two-degrees-offreedom system for wheel traction applications," IEEE Transactions on Industrial Electronics, vol. 65, no. 6, pp. 4483-4491, 2018.

[3] P. Wheeler and S. Bozhko, "The more electric aircraft: Technology and challenges." IEEE Electrification Magazine, vol. 2, no. 4, pp. 6-12, 2014.

[4] Y. Jia and K. Rajashekara, "Induction machine for more electric aircraft: Enabling new electrical power system architectures," IEEE Electrification Magazine, vol. 5, no. 4, pp. 25-37, 2017.

[5] Y. Huangfu, S. Pang, B. Nahid-Mobarakeh, L. Guo, A. K. Rathore, and F. Gao, "Stability analysis and active stabilization of on-board dc power converter system with input filter," IEEE Transactions on Industrial Electronics, vol. 65, no. 1, pp. 790-799, 2018.

[6] A. Al-Timimy, P. Giangrande, M. Degano, Z. Xu, M. Galea, C. Gerada, G. L. Calzo, H. Zhang, and L. Xia, "Design and losses analysis of a high power density machine for flooded pump applications," IEEE Transactions on Industry Applications, 2018.

[7] V. Madonna, P. Giangrande, and M. Galea, "Electrical power generation in aircraft: review, challenges and opportunities," IEEE Transactions on Transportation Electrification, 2018.
[8] W. Cao, B. C. Mecrow, G. J. Atkinson, J. W. Bennett, and D. J. Atkinson, "Overview of electric motor technologies used for more electric aircraft (mea)." IEEE transactions on industrial electronics, vol. 59, no. 9, pp. 3523-3531, 2012.

[9] V. Madonna, P. Giangrande, C. Gerada, and M. Galea, "Thermal analysis of fault-tolerant electrical machines for more electric aircraft applications," The Journal of Engineering, vol. 2018, no. 13, pp. 461467, 2018

[10] Z. Huang, T. Yang, P. Giangrande, P. Wheeler, and M. Galea, "An effective hybrid space vector pwm technique to improved inverter performance," in Power Electronics Conference (SPEC), 2017 IEEE Southern, pp. 1-6. IEEE, 2017.

[11] G. L. Calzo, P. Zanchetta, C. Gerada, A. Lidozzi, M. Degano, F. Crescimbini, and L. Solero, "Performance evaluation of converter topologies for high speed starter/generator in aircraft applications," in Industrial Electronics Society, IECON 2014-40th Annual Conference of the IEEE, pp. 1707-1712. IEEE, 2014.

[12] X. Jiang, W. Huang, R. Cao, Z. Hao, and W. Jiang, "Electric drive system of dual-winding fault-tolerant permanent-magnet motor for aerospace applications," IEEE Transactions on Industrial Electronics, vol. 62, no. 12 , pp. 7322-7330, 2015

[13] W. Zhao, B. Wu, Q. Chen, and J. Zhu, "Fault-tolerant direct thrust force control for a dual inverter fed open-end winding linear vernier permanent-magnet motor using improved svpwm,' IEEE Transactions on Industrial Electronics, vol. 65, no. 9, pp. 7458-7467, 2018.

[14] S. Lakhimsetty, N. Surulivel, and V. Somasekhar, "Improvised svpwm strategies for an enhanced performance for a four-level open-end winding induction motor drive," IEEE Transactions on Industrial Electronics, vol. 64, no. 4, pp. 2750-2759, 2017.

[15] M. H. V. Reddy, T. B. Reddy, B. R. Reddy, and M. S. Kalavathi, "Discontinuous pwm technique for the asymmetrical dual inverter configuration to eliminate the overcharging of dc-link capacitor,' IEEE Transactions on Industrial Electronics, vol. 65, no. 1, pp. 156-166, 2018.

[16] M. S. Toulabi, J. Salmon, and A. M. Knight, "Design, control, and experimental test of an open-winding ipm synchronous motor," IEEE Transactions on Industrial Electronics, vol. 64, no. 4, pp. 2760-2769, 2017.

[17] B. P. Reddy and S. Keerthipati, "A multilevel inverter configuration for an open-end-winding pole-phase-modulated-multiphase induction motor drive using dual inverter principle," IEEE Transactions on Industrial Electronics, vol. 65, no. 4, pp. 3035-3044, 2018.

[18] S. Chowdhury, P. W. Wheeler, C. Patel, and C. Gerada, "A multilevel converter with a floating bridge for open-end winding motor drive applications," IEEE Transactions on Industrial Electronics, vol. 63, no. 9, pp. 5366-5375, 2016.

[19] S. Chowdhury, P. W. Wheeler, C. Gerada, and C. Patel, "Model predictive control for a dual-active bridge inverter with a floating bridge," IEEE Transactions on Industrial Electronics, vol. 63, no. 9, pp. 5558-5568, 2016.

[20] M. Priestley, J. E. Fletcher, and C. Tan, "Space-vector pwm technique for five-phase open-end winding pmsm drive operating in the overmodulation region," IEEE Transactions on Industrial Electronics, vol. 65 , no. 9, pp. 6816-6827, 2018.

[21] A. D. Kiadehi, K. E. K. Drissi, and C. Pasquier, "Voltage thd reduction for dual-inverter fed open-end load with isolated dc sources," IEEE Transactions on Industrial Electronics, vol. 64, no. 3, pp. 2102-2111, 2017.

[22] S. K. Giri, S. Chakrabarti, S. Banerjee, and C. Chakraborty, "A carrierbased pwm scheme for neutral point voltage balancing in three-level inverter extending to full power factor range," IEEE Transactions on Industrial Electronics, vol. 64, no. 3, pp. 1873-1883, 2017.

[23] W. Li, J. Hu, S. Hu, H. Yang, H. Yang, and X. He, "Capacitor voltage balance control of five-level modular composited converter with hybrid space vector modulation," IEEE Transactions on Power Electronics, vol. 33, no. 7, pp. 5629-5640, 2018.

[24] S. Pramanick, R. S. Kaarthik, K. Gopakumar, F. Blaabjerg et al., "Extending the linear modulation range to the full base speed using a single dc-link multilevel inverter with capacitor-fed h-bridges for im drives," IEEE Transactions on Power Electronics, vol. 32, no. 7, pp. 5450-5458, 2017

[25] J. Pereda and J. Dixon, "Cascaded multilevel converters: Optimal asymmetries and floating capacitor control," IEEE Transactions on Industrial Electronics, vol. 60, no. 11, pp. 4784-4793, 2013.

[26] K. A. Corzine, M. W. Wielebski, F. Peng, and J. Wang, "Control of cascaded multi-level inverters," in Electric Machines and Drives Conference, 2003. IEMDC'03. IEEE International, vol. 3, pp. 15491555. IEEE, 2003 
[27] Y. Ohto, T. Noguchi, and T. Sasaya, "Space vector modulation of dua inverter with battery and capacitor across dc buses," in Power Electronics and Drive Systems (PEDS), 2017 IEEE 12th International Conference on, pp. 1-172. IEEE, 2017.

[28] J. Ewanchuk, J. Salmon, and C. Chapelsky, "A method for supply voltage boosting in an open-ended induction machine using a dual inverter system with a floating capacitor bridge," IEEE Transactions on Power Electronics, vol. 28, no. 3, pp. 1348-1357, 2013.

[29] M. Mengoni, A. Amerise, L. Zarri, A. Tani, G. Serra, and D. Casadei,
"Control scheme for open-ended induction motor drives with a floating capacitor bridge over a wide speed range," IEEE Transactions on Industry Applications, 2017.

[30] D. Lusignani, D. Barater, G. Franceschini, G. Buticchi, M. Galea, and C. Gerada, "A high-speed electric drive for the more electric engine," in Energy Conversion Congress and Exposition (ECCE), 2015 IEEE, pp. 4004-4011. IEEE, 2015. 